\title{
CHANGES IN PHYSICAL-MECHANICAL PROPERTIES AND CHEMICAL COMPOSITIONS OF TOONA SINENSIS WOOD BEFORE AND AFTER THERMAL TREATMENT
}

\author{
Jiulong Xie, Lin Chen, Huijuan Shao, Lu He, Yongze Jiang, Dan Lu, \\ Hui Xiao, Yuzhu Chen, Xingyan Huang, Jianfeng Hao, Lihua Tu, Tiantian Lin, \\ Yinlong Xiao, Gang Chen, Jineiu Qi \\ Sichuan Agricultural University \\ CHINA \\ (Received February 2020)
}

\begin{abstract}
Vacuum heat treatment was used to improve the dimensional stability of Toona sinensis wood in this study, the shrinking and swelling rates, the physical-mechanical properties, and the chemical compositions before and after the thermal treatment were evaluated. The results revealed that the volume shrinkage and swelling rate for the heat-treated wood samples were decreased by $45.60 \%$ and $49.95 \%$, respectively at $220^{\circ} \mathrm{C}$ for $6 \mathrm{~h}$ indicating that thermal treatment could obviously improve the dimensional stability of Toona sinensis wood. Thermal treatment also decreased the mechanical strength. The surface color was changed by the treatment. The chemical composition results showed the decrease in density and mechanical strength was due to the partial degradation of hemicellulose during the treatment. The results of this study that vacuum heat treatment could improve the dimensional stability by sacrificing somewhat mechanical strength, the treatment conditions mainly the temperature should be properly controlled to archive an optimized improvement in dimensional stability with minimum reduction in mechanical strength.
\end{abstract}

KEYWORDS: Toona sinensis, thermal treatment, physical-mechanical properties, chemical composition.

\section{INTRODUCTION}

Toona sp. wood (Toona ciliata Roem.), a commercial wood species in China, has been widely used in solid wood furniture, structure, and interior decoration. The fast growth rate Toona sp. wood and its attractive reddish-brown heartwood surface color of Toona sp. wood and has broaden its utilizations (Xia et al. 2018). However, the discoloration, warping, and cracking problems caused by aging, shrink and or swelling reduced the quality and service life of the 
product made from Toona sp. wood (Sun et al. 2019). Therefore, wood modification process should be applied to improve the wood quality of Toona sp. wood prior to its usage (Esteves and Pereira 2008). Thermal treatment has been proved to be an efficient and environmental friendly method to improve many properties of wood such as the dimensional stability, decay durability, and resistance ability against rot, etc. (Bekhta and Niemz 2003, Candelier et al. 2013, Huang et al. 2012, Kačíková et al. 2013, Kamdem et al. 2002, Kesik et al. 2014, Priadi and Hiziroglu 2013, Šušteršic et al. 2010). Thus, in order to improve certain properties of Toona sp. wood, vacuum heat treatment was used.

The purpose of this paper was to evaluate the effect of treatment temperature and time on the dimensional stability, mechanical strength, color, and chemical compositions. The results of this study will provide fundamental information for industrial modification of Toona sp. wood for commercial production.

\section{MATERIAL AND METHODS}

\section{Materials}

Toona sp. trunks were harvested from Dechang, Sichuan, China. The age of the harvested wood was 53-year-old. Lumbers with thickness $30 \mathrm{~cm}$ were prepared and air dried. For the preparation of the thermal treated samples, the lumbers were placed in a vacuum oven and maintained under different conditions. The treatment temperature in this study was controlled in the range of $160-200^{\circ} \mathrm{C}$ with an internal of $20^{\circ} \mathrm{C}$. For each treatment temperature, the samples were maintained for $2 \mathrm{~h}, 4 \mathrm{~h}$, and $6 \mathrm{~h}$, respectively. After the treatment, the samples were cured in the external environment for one week for further analysis.

\section{Dimensional stability}

The volume shrinkage and swelling were determined in accordance with Chinese standard methods of GBT 1932-2009 and GBT 1934-2009, respectively.

\section{Mechanical strength}

The mechanical strength including compressive strength, modulus of rupture, and modulus of elasticity were determined according to Chinese standard methods of GBT 1935-2009, GBT 1936.1-2009, and GBT 1936.2-2009, respectively.

\section{Chemical composition}

The determination of holocellulose, hemicellulose, Klason lignin, and $1 \% \mathrm{NaOH}$ solubility content was according to standard methods of ASTM D 1104-56, ASTM D 1106-96, ASTM D 1109-84.

\section{Color measurement}

The color measurement was carried out by using a high-quality computer colorimeter (NR69CP, Shenzhen Threenh Technology Co., Ltd., Shenzhen, China) with a D65 light source and a measuring aperture of $3 \mathrm{~mm}$. For each sample, 25 points were measured, and the mean value was taken. According to the TAPPI T524 om-79 (1979), in the CIELAB color system, L* is the value on the white/black axis, $a^{*}$ is the value on the red /green axis, and $b^{*}$ is the value on the blue/yellow axis. The $\mathrm{a}^{*}$ value best represents the difference in green and red, where a smaller $\mathrm{a}^{*}$ value indicates a greener sample color. 


\section{RESULTS AND DISCUSSION}

\section{Effect of heat treatment on the volume shrinkage and swelling}

Shrinkage and swelling of wood are two important factors indicating the dimensional stability of wood. The lower values in shrinkage and swelling signify better dimensional stability (Korkut and Guller 2008).
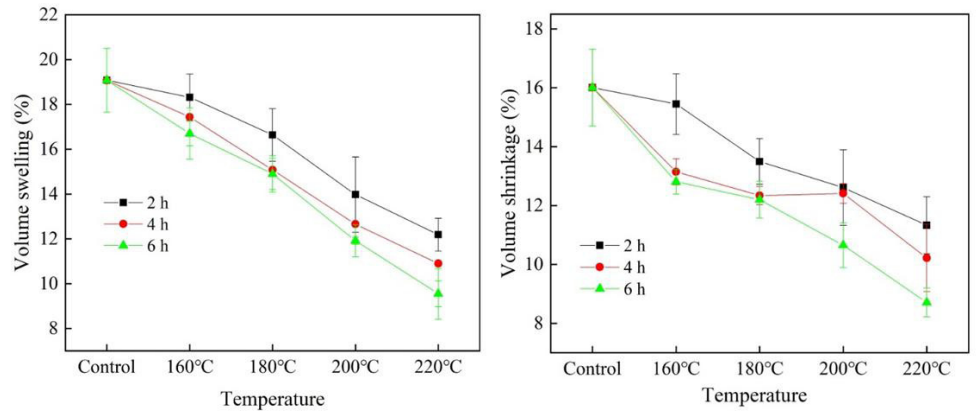

Fig. 1: Volume shrinkage and swelling of Toona sinensis wood before and after heat treatment.

As shown in Fig. 1, compared to the control, the volume shrinkage and swelling rate for the heat-treated wood samples decreased by $3.50 \%-45.60 \%$ and $3.98 \%-49.95 \%$, resp. The volume shrinkage and swelling rate for the wood samples treated at $160^{\circ} \mathrm{C}$ for $6 \mathrm{~h}$ decreased by $19.99 \%$ and $12.47 \%$, resp. At the treatment temperature of $160^{\circ} \mathrm{C}$, no obvious decrease in volume shrinkage and swelling rate was observed with prolonging the treatment time. Further increased the treatment temperature, the volume shrinkage and swelling rate obviously decreased. For example, the volume shrinkage and swelling rate for the wood samples treated at $220^{\circ} \mathrm{C} / 2$ $\mathrm{h}$ decreased by $29.23 \%$ and $36.11 \%$, respectively. Similar to the effect of time at $160^{\circ} \mathrm{C}$, further increase in time at $220^{\circ} \mathrm{C}$ will not either obviously decrease the values in volume shrinkage or the swelling rate. Fig. 1 indicates that with increasing the heat treatment temperature or prolonging the treatment time, both the volume shrinkage and the swelling rate decreased, indicating that heat treatment could improve the dimensional stability and the improvement was largely depend on the heat treatment temperature, the results were consistent with the study of the improvement of mechanical properties of oak heat treatment (Zhao et al. 2019, Darius et al. 2020). Improved dimensional stability by heat treatment was also proved to be effective on White poplar, Spruce, Pinus sylvestris, and Acacia hybrid wood (Feng and Zhao 2011, Tuong and Li 2011). Previous research indicated that the reduction in shrinkage or swelling rate of wood induced by heat treatment was due to the degradation in polyoses components and the formation of hydrophobic constitutes during the treatment (Herrera et al. 2014).

\section{Effect of heat treatment on the chemical compositions}

The chemical compositions of the control and heat treated wood samples are presented in Tab. 1. As shown in Tab. 1, the holocellulose and hemicellulose contents of the Toona sinensis wood decreased with increasing the treatment temperature or prolonging the time. The holocellulose and hemicellulose contents for the wood samples treated under $160^{\circ} \mathrm{C}$ for $2 \mathrm{~h}$ decreased by $5.93 \%$ and $7.90 \%$, respectively, revealing that holocellulose and hemicellulose started to degrade from $160^{\circ} \mathrm{C}$. When the temperature increased to $200^{\circ} \mathrm{C}$ and kept for $6 \mathrm{~h}$, the holocellulose and hemicellulose contents obviously decreased by $15.24 \%$ and $23.78 \%$, respectively, 
indicating the severity degradation of holocellulose and hemicellulose. The decrement for hemicellulose was larger than that for holocellulose. The degradation temperature range for hemicellulose, cellulose, and lignin was $180-300^{\circ} \mathrm{C}, 240-400^{\circ} \mathrm{C}$, and $280-550^{\circ} \mathrm{C}$, respectively. Therefore, the reduction in holocellulose was mainly due to the degradation in hemicellulose (Yildiz et al. 2006). Heat treatment also caused reduction in hemicellulose content in wood species such as spruce, beech, and Chinese fir wood. (Cheng et al. 2016, Windeisen et al. 2007). Further increasing the temperature to $220^{\circ} \mathrm{C}$ for $6 \mathrm{~h}$, the hemicellulose content for the treated samples was as low as $11.14 \%$, decreased by $66 \%$ compared to the control. This result indicated that increasing temperature will accelerate the degradation of hemicellulose. The obvious changes in hemicellulose content with response to treatment temperature over $200^{\circ} \mathrm{C}$ may be due to the relatively low molecular weight compared to cellulose and lignin (González-Peña et al. 2009, Severo et al. 2016).

Tab. 1: Changes in chemical compositions of Toona sinensis wood before and after heat treatment.

\begin{tabular}{|c|c|c|c|c|c|}
\hline Temperature & Time & $\begin{array}{c}\text { Holocellulose } \\
(\%)\end{array}$ & $\begin{array}{c}\text { Hemicellulose } \\
(\%)\end{array}$ & $\begin{array}{c}\text { Lignin } \\
(\%)\end{array}$ & $\begin{array}{c}1 \% \mathrm{NaOH} \\
\text { extractives (\%) }\end{array}$ \\
\hline \multicolumn{2}{|c|}{ Control } & $78.61 \pm 0.15$ & $32.67 \pm 0.35$ & $27.16 \pm 0.42$ & $20.75 \pm 0.16$ \\
\hline \multirow{3}{*}{$160^{\circ} \mathrm{C}$} & $2 \mathrm{~h}$ & $74.61 \pm 1.08$ & $30.65 \pm 0.32$ & $30.62 \pm 1.11$ & $21.36 \pm 0.09$ \\
\hline & $4 \mathrm{~h}$ & $74.53 \pm 0.31$ & $30.91 \pm 0.19$ & $30.51 \pm 0.37$ & $21.31 \pm 0.28$ \\
\hline & $6 \mathrm{~h}$ & $72.72 \pm 0.98$ & $28.72 \pm 0.48$ & $32.19 \pm 0.14$ & $21.38 \pm 0.42$ \\
\hline \multirow{3}{*}{$180^{\circ} \mathrm{C}$} & $2 \mathrm{~h}$ & $73.19 \pm 0.37$ & $28.60 \pm 0.35$ & $30.90 \pm 0.10$ & $21.43 \pm 0.16$ \\
\hline & $4 \mathrm{~h}$ & $72.79 \pm 0.74$ & $28.57 \pm 0.68$ & $31.01 \pm 0.62$ & $21.38 \pm 0.47$ \\
\hline & $6 \mathrm{~h}$ & $71.23 \pm 0.77$ & $27.69 \pm 0.37$ & $33.06 \pm 0.10$ & $21.38 \pm 0.42$ \\
\hline \multirow{3}{*}{$200^{\circ} \mathrm{C}$} & $2 \mathrm{~h}$ & $72.26 \pm 0.49$ & $27.93 \pm 0.22$ & $31.23 \pm 0.27$ & $21.73 \pm 0.13$ \\
\hline & $4 \mathrm{~h}$ & $70.47 \pm 0.46$ & $27.09 \pm 0.23$ & $32.06 \pm 0.16$ & $21.81 \pm 0.17$ \\
\hline & $6 \mathrm{~h}$ & $66.63 \pm 0.66$ & $24.90 \pm 0.55$ & $35.65 \pm 0.17$ & $21.82 \pm 0.13$ \\
\hline \multirow{3}{*}{$220^{\circ} \mathrm{C}$} & $2 \mathrm{~h}$ & $65.17 \pm 0.79$ & $14.83 \pm 0.18$ & $32.89 \pm 0.53$ & $21.76 \pm 0.15$ \\
\hline & $4 \mathrm{~h}$ & $63.80 \pm 0.12$ & $14.10 \pm 1.10$ & $32.93 \pm 0.09$ & $21.82 \pm 0.11$ \\
\hline & $6 \mathrm{~h}$ & $58.99 \pm 0.50$ & $11.14 \pm 1.31$ & $38.54 \pm 0.07$ & $21.85 \pm 0.56$ \\
\hline
\end{tabular}

With contrast to the decrease in carbohydrate content with respect to heat treatment, the lignin content of the heat treated samples increased after the treatment. This may be due to the fact that the relative low carbohydrate content resulted in the relative high lignin content during the determination producer. Another reason may be that the decomposed hemicellulose derivatives re-condensed into insoluble large molecular substances, which lead to the increase in the lignin content by using the wet chemistry method (Huang et al. 2010). The $1 \% \mathrm{NaOH}$ extractive content of the heat treated samples was a little bit higher than that of the control. The slight increase in $1 \% \mathrm{NaOH}$ extractive after heat treatment may be because of the small molecular substances from the decomposition of large molecular substances such as hemicellulose and cellulose (Gupta and Lee 2010). An interesting finding was that the $1 \% \mathrm{NaOH}$ extractive almost kept unchanged with increasing the temperature or prolonging the time, which indicated the degree of the decomposed large molecular substances was limited .

\section{Effect of heat treatment on the density and mechanical strength}

Fig. 2 shows the physical-mechanical properties of Toona sinensis wood with response to temperature and time. 

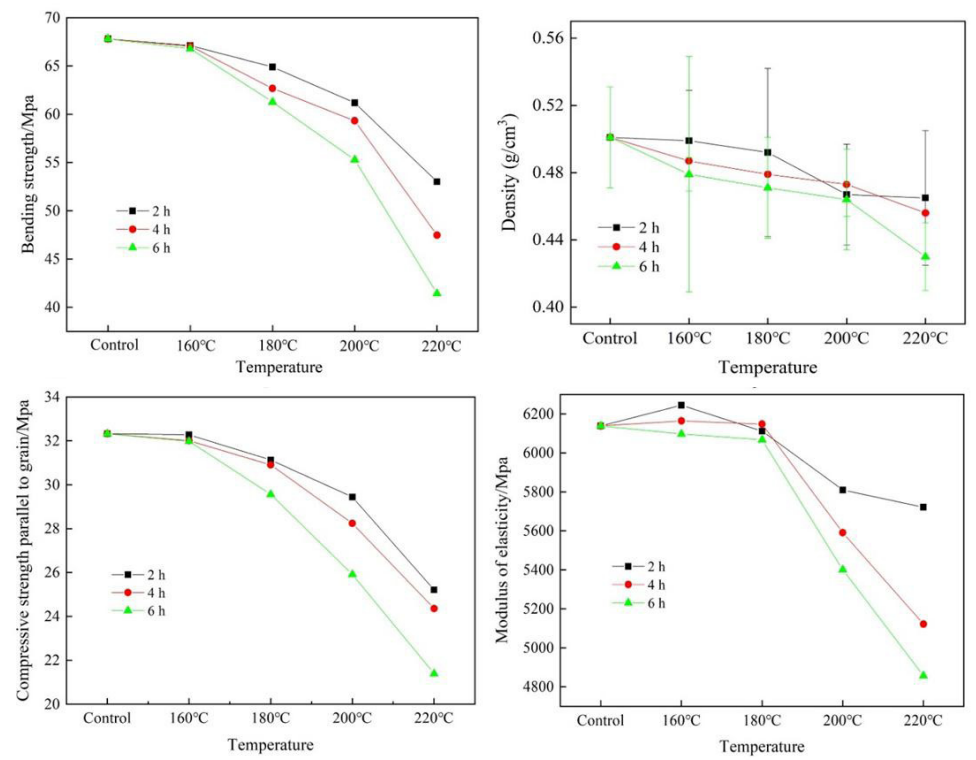

Fig. 2: Density, bending strength, modulus of elasticity and Compressive strength parallel to grain of Toona sinensis wood before and after treatment.

As shown in Fig. 2, the heat treatment resulted in the reduction in density and mechanical strength, and the density showed decreased trend with increasing the treatment temperature or prolong the time. The density for the samples treated at $220^{\circ} \mathrm{C}$ for $6 \mathrm{~h}$ was decreased to $0.430 \mathrm{~g}^{\mathrm{cm}}{ }^{-3}$, decreased by $14.17 \%$ compared to that for the control. The decrement in density caused by the temperature was not obvious in the temperature range of $160-200^{\circ} \mathrm{C}$, which with increasing the temperature to $220^{\circ} \mathrm{C}$, the density was significantly decreased. The reduction in density after treatment may be due to that substance composing of the cell wall was decomposed resulting in the mass deduction (Decoux et al. 2004, Taghiyari et al.2020). The effect of heat treatment on the density of Toona sinensis wood was similar to that for Eucalyptus wood (Gao et al. 2013). Compared to the control, the bending strength, and compressive strength decreased by $1.03 \%-38.92 \%$ and $0.15 \%-33.84 \%$, respectively. The mechanical strength significantly decreased at $200^{\circ} \mathrm{C}$. The decrease in mechanical strength may be due to the decomposition of the cell wall components during the heat treatment as evidenced in the chemical analysis (Yildiz et al. 2006).

\section{Effect of heat treatment on the surface color}

After heat treatment, the surface color of the wood samples was changed from red yellow to dark brown from. As shown in Tab. 2, the $L^{*}$ and $b^{*}$ values slightly decreased with increasing treatment temperature and time. Compared to the control, the $\mathrm{L}^{*}$ value indicating the brightness for the treated samples decreased by $0.39 \%-43.81 \%$, revealing that heat treatment induced the color change from white to black. The $b^{*}$ values decreased by $8.86 \%-31.99 \%$ indicated that the color of treated samples changed from yellow to blue. No specific patter was observed in a* values with respect to treatment temperature. The $\Delta \mathrm{E}^{*}$ value significantly increased from 3.75 to 29.33 as the treatment condition changes from $160 / 2 \mathrm{~h}$ to $220 / 6 \mathrm{~h}$, indicating significant 
chromatic aberration existed between the heat treated samples and the control. This may be due to that new colored matter formed during the treatment process (Tjeerdsma and Militz 2005). Moreover, the decomposition of the extractives under high treatment temperature may also induce the color change of the wood samples (Chen and Gao 2009).

Tab. 2: Color parameters of Toona sinensis wood samples before and after heat treatment.

\begin{tabular}{|c|c|c|c|c|c|c|c|c|}
\hline Temperature & Time & $\mathrm{L}^{*}$ & $\mathrm{a}^{*}$ & $\mathrm{~b}^{*}$ & $\Delta \mathrm{L}^{*}$ & $\Delta \mathrm{a}^{*}$ & $\Delta \mathrm{b}^{*}$ & $\Delta \mathrm{E}^{*}$ \\
\hline Control & & $58.20 \pm 3.06$ & $18.99 \pm 2.24$ & $34.89 \pm 3.69$ & & & & \\
\hline \multirow{3}{*}{$160^{\circ} \mathrm{C}$} & $2 \mathrm{~h}$ & $57.97 \pm 2.84$ & $21.19 \pm 1.12$ & $31.86 \pm 2.04$ & -0.23 & 2.2 & -3.03 & 3.75 \\
\cline { 2 - 9 } & $4 \mathrm{~h}$ & $57.18 \pm 3.22$ & $17.04 \pm 1.11$ & $26.53 \pm 2.45$ & -1.02 & -1.95 & -8.36 & 8.64 \\
\cline { 2 - 9 } & $6 \mathrm{~h}$ & $56.05 \pm 2.64$ & $17.08 \pm 2.28$ & $29.16 \pm 2.13$ & -2.15 & -1.91 & -5.73 & 6.41 \\
\hline \multirow{3}{*}{$180^{\circ} \mathrm{C}$} & $2 \mathrm{~h}$ & $57.39 \pm 2.34$ & $19.86 \pm 3.32$ & $27.27 \pm 2.26$ & -0.81 & 0.87 & -7.62 & 7.71 \\
\cline { 2 - 9 } & $4 \mathrm{~h}$ & $54.82 \pm 3.52$ & $17.26 \pm 3.45$ & $26.62 \pm 2.30$ & -3.38 & -1.73 & -8.27 & 9.1 \\
\cline { 2 - 9 } & $6 \mathrm{~h}$ & $49.52 \pm 2.44$ & $18.33 \pm 3.67$ & $25.45 \pm 1.53$ & -8.68 & -0.66 & -9.44 & 12.84 \\
\hline \multirow{3}{*}{$200^{\circ} \mathrm{C}$} & $2 \mathrm{~h}$ & $50.62 \pm 2.01$ & $20.76 \pm 3.72$ & $26.04 \pm 1.39$ & -2.58 & 1.77 & -8.85 & 9.39 \\
\cline { 2 - 9 } & $4 \mathrm{~h}$ & $48.30 \pm 3.18$ & $16.05 \pm 1.86$ & $25.05 \pm 1,63$ & -9.9 & -2.94 & -9.84 & 14.26 \\
\cline { 2 - 8 } & $6 \mathrm{~h}$ & $40.89 \pm 4.24$ & $11.94 \pm 2.27$ & $24.66 \pm 1.80$ & -17.31 & -7.05 & -10.23 & 21.31 \\
\hline \multirow{3}{*}{$220^{\circ} \mathrm{C}$} & $2 \mathrm{~h}$ & $41.31 \pm 4.91$ & $14.36 \pm 1.90$ & $25.63 \pm 1.90$ & -11.89 & -1.63 & -9.26 & 15.16 \\
\cline { 2 - 8 } & $4 \mathrm{~h}$ & $38.59 \pm 3.30$ & $11.16 \pm 2.69$ & $24.75 \pm 2.22$ & -19.61 & -7.83 & -10.14 & 23.42 \\
\cline { 2 - 8 } & $6 \mathrm{~h}$ & $32.71 \pm 1.65$ & $9.72 \pm 2.61$ & $23.73 \pm 2.21$ & -25.49 & -9.27 & -11.16 & 29.33 \\
\hline
\end{tabular}

\section{CONCLUSIONS}

The volume shrinkage and swelling rate of the Toona sinensis wood samples were decreased by the thermal treatment, and showed an continuous decreasing pattern with increasing the treatment temperature or prolong the treatment time. The decreasing in the volume shrinkage and swelling rate indicated the improvement in the dimensional stability. However, the thermal treatment also resulted in the reduction in the density and mechanical strength of the Toona sinensis wood, and the decrement value increased with respect to the temperature and time. The hemicellulose content in the Toona sinensis wood was obviously decreased, and the hemicellulose content for the treated samples was as low as $11.14 \% 220^{\circ} \mathrm{C}$ for $6 \mathrm{~h}$. The degradation in the hemicellulose may provide evidence on the decrease in the shrinkage and swelling rate and the reduction in the density and mechanical strength. The surface color of the thermal treated samples was changed from red yellow to dark brown. The results of this study may provide fundamental information for industrial practice production of thermal treated Toona sinensis wood.

\section{REFERENCES}

1. Bekhta, P., Niemz, P., 2003: Effect of high temperature on the change in color, dimensional stability and mechanical properties of spruce wood. Holzforschung 57(5): 539-546.

2. Candelier, K., Dumarçay, S., Pétrissans, A., Desharnais, L., Gérardin, P., Pétrissans, M., 2013: Comparison of chemical composition and decay durability of heat treated wood cured under different inert atmospheres. Polymer degradation and Stability 98(2): 677- 681. 
3. Chen, Y., Gao, J.M., 2009: Spectrum analysis on heat-induced discoloration of dioxane extractives from locust (Robinia pseudoacacia). Wood Journal of Beijing Forestry University 31(S1): 90-93.

4. Cheng, S., Huang, A., Wang, S., Zhang, Q. 2016: Effect of different heat treatment temperatures on the chemical composition and structure of Chinese fir wood. Bioresources 11(2): 4006-4016.

5. Darius, A., Milda J., Yaida D., 2020: The influence of thermal modification on the resistance to water impact properties and strength of wood used in outdoor conditions 65(3): 353-364

6. Decoux, V., Varcin, É., Leban, J.M., 2004: Relationships between the intra-ring wood density assessed by X-ray densitometry and optical anatomical measurements in conifers. Consequences for the cell wall apparent density determination. Annals of Forest Science 61(3): 251-262.

7. Esteves, B., Pereira, H., 2008: Wood modification by heat treatment: A review. Bioresources 4(1): 370-404.

8. Feng, D., Zhao, J., 2011: Heat treatment of wood hygroscopicity and dimensional stability. Journal of Northwest Forestry University 26(2): 200-202.

9. Gao, W., Luo, J., Li, Q. 2013: Physical and mechanical properties of fast-growing eucalypt wood under high temperature heat treatment. Journal of Southern Agriculture 44(1): 116-120.

10. González-Peña, M.M., Curling, S.F., Hale, M.D., 2009: On the effect of heat on the chemical composition and dimensions of thermally-modified wood. Polymer degradation and stability 94: 2184-2193.

11. Gupta, R., Lee, Y.Y., 2010: Investigation of biomass degradation mechanism in pretreatment of switchgrass by aqueous ammonia and sodium hydroxide. Bioresource technology 101(21): 8185-8191.

12. Herrera, R., Erdocia, X., Llano-Ponte, R., Labidi, J., 2014: Characterization of hydrothermally treated wood in relation to changes on its chemical composition and physical properties. Journal of analytical and Applied Pyrolysis 107: 256-266.

13. Huang, R., Cao, Y., Zhao, X., Zhao, Y., Zhou, Y., Wu, Y., 2010: Impact of heat treatment on chemical composition of Chinese white poplar wood. Journal of Beijing Forestry University $32: 155-160$.

14. Huang, X., Kocaefe, D., Kocaefe, Y., Boluk, Y., Pichette, A., 2012: Changes in wettability of heat-treated wood due to artificial weathering. Wood science and technology 46: 1215-1237.

15. Kačíková, D., Kačík, F., Čabalová, I., Ďurkovič, J., 2013: Effects of thermal treatment on chemical, mechanical and colour traits in Norway spruce wood. Bioresource Technology 144: 669-674.

16. Kamdem, D.P., Pizzi, A., Jermannaud, A., 2002: Durability of heat-treated wood. Holz als Roh-und Werkstoff 60: 1-6.

17. Kesik, H.I., Korkut, S., Hiziroglu, S., Sevik, H., 2014: An evaluation of properties of four heat treated wood species. Industrial Crops and Products 60: 60-65.

18. Korkut, D.S., Guller, B., 2008: The effects of heat treatment on physical properties and surface roughness of red-bud maple (Acer trautvetteri Medw.) wood. Bioresource technology 99(8): 2846-2851.

19. Priadi, T., Hiziroglu, S., 2013: Characterization of heat treated wood species. Materials \& Design 49: 575-582. 
20. Sun, B., Wang, Z., Liu, J., 2019: Study on color and surface chemical properties of eucalyptus pellita wood subjected to thermo-vacuum treatment. Wood Research 64(1): $1-12$.

21. Severo, E.T.D., Calonego, F.W., Sansígolo, C.A., Bond, B., 2016: Changes in the chemical composition and decay resistance of thermally-modified Hevea brasiliensis wood. PloS one 11: e151353.

22. Šušteršic, Ž., Mohareb, A., Chaouch, M., Pétrissans, M., Petrič, M., Gérardin, P., 2010: Prediction of the decay resistance of heat treated wood on the basis of its elemental composition. Polymer Degradation and Stability 95: 94-97.

23. Taghiyari, H. R., Esmailpour, A., Adamopoulos, S., Zereshki, K., Hosseinpourpia, R., 2020: Shear strength of heat-treated solid wood bonded with polyvinyl-acetate reinforced by nanowollastonite. Wood Research 65(2): 183-194.

24. Tjeerdsma, B.F., Militz, H., 2005: Chemical changes in hydrothermal treated wood: FTIR analysis of combined hydrothermal and dry heat-treated wood. Holz als roh-und Werkstoff 63: 102-111.

25. Tuong, V.M., Li, J., 2011: Changes caused by heat treatment in chemical composition and some physical properties of acacia hybrid sapwood. Holzforschung 65(1): 67-72

26. Windeisen, E., Strobel, C., Wegener, G., 2007: Chemical changes during the production of thermo-treated beech wood. Wood Science and Technology 41(6): 523-536.

27. Xia, L., Q.J., Huang, X., Xie, J., Xiao, H., Luo, J., Xiao, X., Song, L., 2018: Physicalmechanical properties of heartwood and sapwood in Toona sp. wood (Toona ciliata M. Roem.) before and after accelerated aging treatment. Bioresources 13: 8409-8420.

28. Yildiz, S., Gezer, E.D., Yildiz, U.C., 2006: Mechanical and chemical behavior of spruce wood modified by heat. Building and environment 41(12): 1762-1766.

29. Zhao, X., Tu, D., Chen, C., Zhou, Q. 2019: Prediction of the mechanical properties of thermally-modified rubber wood on the basic of its surface characteristic. Wood Research 64(1): 25-34.

Jiulong Xie*, Lin Chen, Huijuan Shao, Lu He, Yongze Jiang, Dan Lu, Hui Xiao, Yuzhu Chen, Xingyan Huang, Jianfeng Hao, Lihua Tu, Tiantian Lin,

Gang Chen, Jingiu Qi*

Sichuan Agricultural University

College of Forestry

Chengdu, Sichuan

China, 6irizo

*Corresponding author: qijinqiu2005@aliyun.com

Yinlong XiaO

Sichuan Agricultural University

College of Environment

Chengdu, Sichuan

China, 6irizo 